Dmytro 0. Butov ${ }^{1}$, Mykhaylo M. Kuzhko ${ }^{2}$, Natalia I. Makeeva', Tetyana S. Butova', Hanna L. Stepanenko', Andrii B. Dudnyk ${ }^{3}$

'Kharkiv National Medical University, Kharkiv, Ukraine

${ }^{2}$ National institute of phthisiology and pulmonology named after F. G. Yanovskyi NAMS of Ukraine, Kiev, Ukraine

${ }^{3}$ National Pirogov Memorial Medical University, Vinnytsia, Ukraine

\title{
Association of interleukins genes polymorphisms with multi-drug resistant tuberculosis in Ukrainian population
}

The study was supported by the scholarships for young scientists from the Cabinet Ministers of Ukraine

\begin{abstract}
Introduction: Multi-drug resistant tuberculosis (MDR TB) is a significant health problem in some parts of the world. Three major cytokines involved in TB immunopathogenesis include IL-2, IL-4 and IL-10. The susceptibility to MDR TB may be genetically determined. The aim of the study was to assess the association of IL-2, IL-4, IL-10 gene polymorphisms with multi-drug resistant tuberculosis (MDR TB) in Ukrainian population.

Material and methods: We observed 140 patients suffering from infiltrative pulmonary tuberculosis (PT) and 30 apparently healthy subjects. The patients were assigned to two groups whether they suffer or do not suffer from pulmonary MDR TB. Interleukin gene (IL) polymorphisms, particularly T330G polymorphism in the IL-2 gene, C589T polymorphism in the IL-4 gene and G1082A polymorphism in the IL-10 gene were studied through polymerase chain reaction. Circulating levels of IL-2, IL-4 and IL-10 in venous blood were estimated using ELISA.

Results: Prior to treatment, patients with PT showed significant increase of IL-2 levels and decrease of IL-4 and IL-10 levels compared to apparently healthy subjects. Circulating IL-4 and IL-10 levels were significantly decreased whilst serum IL-2 level was significantly increased in patients with MDR TB compared to non-MDR TB. Low IL-4 and IL-10 secretion and considerable IL-2 alterations were shown to be significantly associated with mutations of homozygous and heterozygous genotypes affecting C589T polymorphism in the IL-4 gene, G1082A polymorphism in the IL-10 gene and T330G polymorphism in the IL-2 gene in patients with PT. Conclusions: Heterozygous genotype and mutations homozygous genotypes gene in polymorphisms determining specified cytokines' production is a PT risk factor and may lead to disease progression into chronic phase. Heterozygous genotype of aforementioned cytokine genetic polymorphisms was significantly the most frequent in patients with MDR TB.
\end{abstract}

Key words: multi-drug resistant tuberculosis; IL-2; IL-4; IL-10; gene polymorphisms

Pneumonol Alergol Pol 2016; 84: 168-173

\section{Introduction}

Mycobacterium tuberculosis (MTB) resistance to antimycobacterial drugs is a problem of immediate interest worldwide [1]. Experts generally agree that the prevalence of multi-drug resistant tuberculosis (MDR TB) has become uncontrolled all over the world; and some countries even consider MDR TB as a threat to national security [2, 3]. There is a growing number of strains that are resistant to one or more anti-TB drugs constituting the main cause for decreasing efficiency of chemotherapy, increasing number of patients with destructive forms, increasing frequency of significant residual post-tuberculosis alterations and increasing incidence of TB relapses. Therefore, an unfavorable epidemiological background for further spread of TB infection 
may occur $[4,5]$. TB incidence associated with multi-drug resistance grows year by year [6].

The real cause why some patients infected with MTB develop the disease accompanied by nonstable immunological response whilst the others demonstrate efficient immunogenic reaction intended to limit pathogen dissemination and prevent the disease remains unclear. Heredity impact on TB development was established in the studies of monozygotic and dizygotic twins. Thus, some evidence indicating that genetics may contribute into susceptibility to TB infection was obtained [7-9].

Multifaceted interaction between pathogen and human immune system is a key factor influencing disease development and progression as well as the efficiency of applied treatment in patients with TB. Cytokines represent an important immunologic agents in MTB control. Three major cytokines involved in TB immunopathogenesis include IL-2, IL-4 and IL-10 [10-13].

There is clear evidence that genetic peculiarities of a human being largely determine susceptibility to infection. Hence, a significant number of patients infected with MTB are apparently healthy subjects who developed an adequate projective immunity whereas only $5-10 \%$ of people have inefficient immunological response that may lead to TB development [14].

Human susceptibility to MTB as an infectious antigen is encoded in various genes with different influence on pathologic phenotype development. Distribution of genotypes predisposed to higher risk of MTB infection and TB development or resistant to these factors is unique for every population and may be the reason for diverse immune response to infectious agent [15].

Moreover, genetic regulation is a complex process of multiple genetic sites correlation [16]. Gene polymorphisms and protein products involved in immunologic protective response determine the degree of MTB resistance as well as disease severity and duration $[17,18]$.

Th1-lymphocytes producing IL-2 play a protective role in TB immunopathogenesis, whereas Th2-lymphocytes producing IL-4 and IL-10 help to maintain function of Th1-lymphocytes. Th1/ Th2-lymphocytes are deemed not to be able to eliminate MTB from human body, probably due to inadequate cellular immune response. Consequently, humoral immune response occurs [10, 19-21].

Considering functional role of IL-2, IL-4 and IL-10 as well as potential genetic variability of polymorphic variants, the study objective was to investigate whether $I L-2, I L-4$ and $I L-10$ gene polymorphisms are associated with MDR TB in Ukrainian population.

\section{Material and methods}

We observed 140 Caucasian patients with infiltrative pulmonary TB permanently residing in Kharkiv and Kharkiv region, Ukraine, aged between 20 and 70 years. The patients were assigned to two groups whether they suffer or do not suffer from pulmonary MDR TB: the first group -74 patients with MDR TB, the second group - 66 patients not suffering from MDR TB (non-MDR TB). Patients were recruited at the Regional TB Hospital no 1 and Regional Anti-TB Dispensary no 1 both in Kharkiv; Regional Anti-TB Dispensary no 3 in Zmeev and Anti-Regional TB Dispensary no 4 in Izyum, both in Kharkiv region. All patients suffered from infiltrating pulmonary TB. All patients were HIV-negative.

The third control group included 30 apparently healthy subjects with comparable age characteristics, no positive history of pulmonary disease, no pathological findings in lungs according to chest X-ray examination, no chronic infectious disease, no acute allergic reactions and respiratory diseases for 3 months prior to the study.

Venous blood sampling was performed in the morning (between 8 and 9 a.m.) on the first days of hospitalization and following two months of patient's staying at hospital. Serum cytokine (IL-2, IL-10 and IL-4) levels were measured using standard ELISA kits.

Molecular methods: Genomic DNA was extracted from blood samples with the «DNA Express» (Liteh Company, Moscow, Russia), according to the manufacturer's instructions. The sets with primers were purchased from Liteh Company (Moscow, Russia) and used it according to the manufacturer's instructions. The method of investigation (for the sets real-time) - an allele-specific PCR using intercalating coloring SybrGreen. T330G - IL-2 rs2069762, C589T IL-4 rs2243250 and G1082A - IL-10 rs1800896 were genotyped with amplification-refractory mutation system-polymerase chain reaction (ARMS-PCR).

Statistics packages MicrosoftExel and Statistica 7.0 were used for statistical analysis. Pearson's chi-square test with Yates' correction for continuity was used to determine if the data are normally distributed. Data received were analyzed using Student's $t$-test. The mean values were considered to be significantly different at $\mathrm{p}<0.05$. Data calculation was also performed 
Table 1. Serum interleukins' levels in patients with pulmonary tuberculosis prior to and following two months of antituberculosis chemotherapy compared with apparently healthy subjects (mean $\pm \mathrm{m}$ ), pg/l

\begin{tabular}{|c|c|c|c|c|c|c|c|}
\hline \multirow[t]{2}{*}{ Groups } & \multirow{2}{*}{$\begin{array}{c}\mathbf{N} \\
\text { case }\end{array}$} & \multicolumn{2}{|c|}{ Interleukin-2 } & \multicolumn{2}{|c|}{ Interleukin-4 } & \multicolumn{2}{|c|}{ Interleukin-10 } \\
\hline & & $\begin{array}{c}\text { Before } \\
\text { treatment }\end{array}$ & $\begin{array}{c}\text { After } \\
2 \text { months of } \\
\text { treatment }\end{array}$ & $\begin{array}{c}\text { Before } \\
\text { treatment }\end{array}$ & $\begin{array}{c}\text { After } \\
2 \text { months of } \\
\text { treatment }\end{array}$ & $\begin{array}{c}\text { Before } \\
\text { treatment }\end{array}$ & $\begin{array}{c}\text { After } \\
2 \text { months of } \\
\text { treatment }\end{array}$ \\
\hline $\begin{array}{l}1^{\text {st }} \text { group - } \\
\text { with MDR TB }\end{array}$ & 74 & $\begin{array}{c}39.34 \pm \\
1.14^{* * \$}\end{array}$ & $\begin{array}{l}32.85 \pm \\
1.11^{* * \# \$}\end{array}$ & $\begin{array}{l}7.96 \pm \\
0.29^{* * \$}\end{array}$ & $\begin{array}{l}17.62 \pm \\
0.54^{* * \# \$}\end{array}$ & $\begin{array}{c}38.01 \pm \\
0.78^{* * \$}\end{array}$ & $\begin{array}{l}44.58 \pm \\
0.78^{* * * * \#}\end{array}$ \\
\hline $\begin{array}{l}2^{\text {nd }} \text { group - } \\
\text { without MDR TB }\end{array}$ & 66 & $\begin{array}{c}36.20 \pm \\
0.89^{* *}\end{array}$ & $\begin{array}{c}25.27 \pm \\
0.65^{* * \#}\end{array}$ & $\begin{array}{c}11.29 \pm \\
0.35^{* *}\end{array}$ & $\begin{array}{l}21.40 \pm \\
0.60^{* * \#}\end{array}$ & $\begin{array}{c}43.88 \pm \\
0.70^{* *}\end{array}$ & $\begin{array}{c}50.59 \pm \\
0.99^{*} \#\end{array}$ \\
\hline $\begin{array}{l}3^{\text {rd }} \text { group - } \\
\text { healthy donors }\end{array}$ & 30 & \multicolumn{2}{|c|}{$21.60 \pm 0.80$} & \multicolumn{2}{|c|}{$29.99 \pm 1.27$} & \multicolumn{2}{|c|}{$50.25 \pm 1.26$} \\
\hline
\end{tabular}

"discrepancy is not significant $(p>0.05)$ when compared with Group 3

"* discrepancy is significant $(p<0.001)$ when compared with Group 3

\#discrepancy is significant $(\mathrm{p}<0.001)$ when compared before treatment and after two months levels among Group

discrepancy is significant $(p<0.001)$ between Groups 1 and 2

using the relative risk (RR) with 95\% probability interval estimation [22].

The project was approved by the Ethics Committee of the Kharkiv National Medical University, Ukraine. It was conducted according to the principles established in the Declaration of Helsinki. Every patient has signed written informed consent and has given his assent for DNA and blood tests as well as relevant clinical data collection.

\section{Results}

Statistically significant increase of serum IL-2 concentration was observed in patients with TB compared to the healthy subjects $(\mathrm{p}<0.05)$. Serum IL-2 level significantly decreased in patients with pulmonary TB following two months of routine treatment compared to IL-2 level prior to treatment. Circulating IL-2 concentration was significantly increased in patients with pulmonary TB following two months of treatment in comparison with the healthy subjects (Table 1).

It was shown that homozygous (GG) and heterozygous (TG) genotypes of T330G polymorphism in the $I L-2$ gene are the most frequent in patients with pulmonary TB $\left(\chi^{2}=34.60, \mathrm{p}<0.01\right)$. Homozygous (TT) genotype of the $I L-2$ gene was the less frequent genetic variant in TB patients. Homozygous (TT) genotype of the $I L-2$ gene was frequent in healthy subjects $(\mathrm{p}<0.01)$ (Table 2). Estimation of relative risk of pulmonary TB development has revealed that carriers of homozygous (GG) or heterozygous (TG) genotypes of T330G polymorphism in the $I L-2$ gene $(R R=1.87,[1.32 ; 2.64], p<0.05)$ are at 1.87 times higher risk to develop the disease than carriers of homozygous genotype (TT) (Table 2).
Investigating TB resistance, we observed a significant prevalence of heterozygous (TG) genotype in the $I L-2$ gene in the MDR TB group compared to the non-MDR TB group. However, homozygous (GG) genotype of the $I L-2$ gene was the most frequent in patients not suffering from MDR TB $\left(\chi^{2}=52.84, p<0.01\right)$. Relative risk of MDR TB development in carriers of heterozygous (TG) genotype of the $I L-2$ gene is 5.22 times higher than in carriers of homozygous (GG and $\mathrm{TT})$ genotypes of the $I L-2$ gene $(\mathrm{RR}=5.22$, [2.74; 9.96], $\mathrm{p}<0.05$ ).

We observed statistically significant decreased serum levels of anti-inflammatory cytokines IL-4 and IL-10 compared with the healthy subjects at the point of treatment onset $(\mathrm{p}<0.05)$. The IL-4 and IL-10 levels were significantly increased in patients with TB compared to the point of treatment onset. Although IL-10 concentrations significantly increased during the first two months of treatment in both TB groups, it was still lower in MDR TB group than that in the controls (Table 1). Serum IL-4 and IL-10 levels were significantly lower in patients with MDR TB prior to chemotherapy and following two months of treatment compared with the non-MDR TB group.

The study revealed correlation between circulating inflammatory cytokines concentrations or level alterations and genotypes of polymorphisms in the $I L-4$ and $I L-10$ genes in the relevant groups of patients with pulmonary TB (Table 2). Our study of C589T and G1082A polymorphisms has shown the prevalence of mutational homozygous and heterozygous genotype polymorphisms of the $I L-4$ and $I L-10$ genes in patients with pulmonary TB (IL- $4-\chi^{2}=24.71$ and IL-10 $-\chi^{2}=34.14, \mathrm{p}<$ 0.01). Polymorphisms of the $I L-4$ and $I L-10$ genes 
Table 2. Distribution of polymorphism genotypes of interleukins in patients with pulmonary tuberculosis and healthy subjects

\begin{tabular}{|c|c|c|c|c|c|c|c|c|c|c|}
\hline \multirow{2}{*}{$\begin{array}{l}\text { Genotype } \\
\text { Groups }\end{array}$} & & \multicolumn{3}{|c|}{$\begin{array}{c}\text { Gene IL-2 } \\
\text { polymorphisms T330G }\end{array}$} & \multicolumn{3}{|c|}{$\begin{array}{c}\text { Gene IL-4 } \\
\text { polymorphism C589T }\end{array}$} & \multicolumn{3}{|c|}{$\begin{array}{c}\text { Gene IL-10 } \\
\text { polymorphism G1082A }\end{array}$} \\
\hline & & TG & GG & $\mathrm{TT}$ & CT & $\mathbf{T T}$ & CC & GA & & GG \\
\hline \multirow{2}{*}{$\begin{array}{c}1^{\text {st }} \text { group - } \\
\text { with MDR TB } \\
\text { (N case }=74)\end{array}$} & $\mathrm{n}$ & 59 & 8 & 7 & 53 & 11 & 10 & 56 & 11 & 7 \\
\hline & $\%$ & $\begin{array}{l}79.73 \pm \\
4.67^{* \# \wedge}\end{array}$ & $\begin{array}{l}10.81 \pm \\
3.61^{8 \wedge \wedge}\end{array}$ & $\begin{array}{c}9.46 \pm \\
3.40\end{array}$ & $\begin{array}{l}71.62 \pm \\
5.24^{* \#^{\wedge}}\end{array}$ & $\begin{array}{l}14.86 \pm \\
4.14^{\varepsilon^{\wedge}}\end{array}$ & $\begin{array}{c}13.51 \pm \\
3.97\end{array}$ & $\begin{array}{l}75.68 \pm \\
4.99^{* \#^{\wedge}}\end{array}$ & $\begin{array}{l}14.86 \pm \\
4.14^{\varepsilon^{\wedge}}\end{array}$ & $\begin{array}{c}9.46 \pm \\
3.40\end{array}$ \\
\hline \multirow{2}{*}{$\begin{array}{c}2^{\text {nd }} \text { group - } \\
\text { without MDR TB } \\
\text { ( } \text { c case }=66 \text { ) }\end{array}$} & $\mathrm{N}$ & 13 & 43 & 10 & 9 & 46 & 11 & 17 & 41 & 8 \\
\hline & $\%$ & $\begin{array}{c}19.70 \pm \\
4.90^{*}\end{array}$ & $\begin{array}{c}65.15 \pm \\
5.87^{* *}\end{array}$ & $\begin{array}{c}15.15 \pm \\
4.41^{s}\end{array}$ & $\begin{array}{c}13.64 \pm \\
4.22^{*}\end{array}$ & $\begin{array}{l}69.70 \pm \\
5.66^{* *}\end{array}$ & $\begin{array}{c}16.67 \pm \\
4.59^{\$}\end{array}$ & $\begin{array}{c}25.76 \pm \\
5.38^{*}\end{array}$ & $\begin{array}{c}62.12 \pm \\
5.97^{* *}\end{array}$ & $\begin{array}{c}12.12 \pm \\
4.02^{\#}\end{array}$ \\
\hline \multirow{2}{*}{$\begin{array}{l}3^{\text {rd }} \text { group - } \\
\text { healthy donors } \\
\text { ( } N \text { case }=30 \text { ) }\end{array}$} & $\mathrm{N}$ & 5 & 7 & 18 & 7 & 6 & 17 & 7 & 6 & 17 \\
\hline & $\%$ & $\begin{array}{c}16.67 \pm \\
6.80^{\#}\end{array}$ & $\begin{array}{c}23.33 \pm \\
7.72^{* *}\end{array}$ & $\begin{array}{c}60.00 \pm \\
8.94\end{array}$ & $\begin{array}{c}23.33 \pm \\
7.72^{\#}\end{array}$ & $\begin{array}{c}20.00 \pm \\
7.30^{* *}\end{array}$ & $\begin{array}{c}56.67 \pm \\
9.05\end{array}$ & $\begin{array}{c}23.33 \pm \\
7.72^{\#}\end{array}$ & $\begin{array}{c}20.00 \pm \\
7.30^{* *}\end{array}$ & $\begin{array}{c}56.67 \pm \\
9.05\end{array}$ \\
\hline
\end{tabular}

"discrepancy is significant $(p<0.05)$ when comparing between mutation homozygote and heterozygous genotype in group

** discrepancy is significant $(p<0.05)$ when comparing between mutation and normal homozygote in group

\#discrepancy is significant $(\mathrm{p}<0.05)$ when comparing between normal homozygote and heterozygous genotype in group

$\$$ discrepancy is not significant ( $p>0.05$ ) when comparing between normal homozygote and heterozygous genotype in group

${ }^{8}$ discrepancy is not significant $(p>0.05)$ when comparing between mutation and normal homozygote in group

discrepancy is significant $(p<0.05)$ when comparing heterozygous genotype between $1^{\text {st }}$ and $2^{\text {nd }}$ group

discrepancy is significant $(p<0.05)$ when comparing mutation homozygote between $1^{\text {st }}$ and $2^{\text {nd }}$ group

discrepancy is not significant $(p>0.05)$ when comparing normal homozygote between $1^{\text {st }}$ and $2^{\text {nd }}$ group

can result in IL-4 and IL-10 level alterations in patients with infiltrative pulmonary TB detected on admission to hospital as well as following two months of treatment. Moreover, we demonstrated that carriers of mutational homozygous or heterozygous genotype of C589T polymorphism in the $I L-4$ gene and polymorphism G1082A in the $I L-10$ gene are at 1.63 times (IL-4) and 1.93 times (IL-10) higher risk to develop the TB than carriers of normal genotype without aforementioned polymorphisms in the genes encoding anti-inflammatory cytokines (IL-4 $-\mathrm{RR}=1.63$, [1.21; 2.18], $\mathrm{p}<0.05$ ) and IL-10 $-\mathrm{RR}=1.93$, [1.33; 2.80], $\mathrm{p}<0.05)$.

At studied C589T polymorphism genotypes of the $I L-4$ gene and G1082A polymorphism genotypes of the $I L-10$ gene we found a significant difference associated with resistant pulmonary TB. Specifically, heterozygous genotype (CT) of the $I L-4$ gene and heterozygous genotype (GA) of the $I L-10$ gene were the most frequent in MDR TB patients group compared with the non-MDR TB group of patients (IL- $4-\chi^{2}=52.33$ and IL-10 $\left.-\chi^{2}=37.69, \mathrm{p}<0.01\right)$. Heterozygous genotype (CT) of the $I L-4$ gene and heterozygous genotype (GA) of the $I L-10$ gene were 4.43 times and 3.62 times more frequent than homozygous genotype respectively in patients with MDR TB (IL-4 - RR $=4.43,[2.58 ; 7.60], \mathrm{p}<0.05$; and IL-10 $-\mathrm{RR}=$ $3.62,[2.11 ; 6.22], \mathrm{p}<0.05)$. These peculiarities were also detected in the non-MDR TB group of patients.

\section{Discussion}

It is well known that alterations in gene promoter region lead to modification of its transcriptional activity. T330G polymorphism located in the IL-2 promoter region should technically result in amino acid replacement in protein subunits corresponding to these polymorphic genes, in relation to origin of transcription and influence the level of gene expression and relevant protein level. Analysis of association between IL-2 secretion and allelic variant of T330G polymorphism in the $I L-2$ gene has shown that patients with TB have a statistically significant increase of serum IL-2 concentration compared to the third group. These changes may correspond to undifferentiated reaction of immune response to MTB elimination. It is well known that IL-2 has an impact on macrophages activation and direct cytotoxicity of T-cells, which accounts for protective role of IL-2 against tuberculosis [23]. On the contrary, it supports the activation of phagocytic elimination of MTB [24].

Serum IL-2 level significantly decreased in patients with pulmonary TB following two months of routine treatment compared to IL-2 level prior to treatment. Circulating IL-2 concentration was significantly increased in patients with pulmonary TB following two months of treatment in comparison with the third group. Considering these changes, we can assume Th1-lymphocyte activity decrease in this group of patients. It may 
indicate a certain stabilization in patients with pulmonary TB taking into account the fact that serum IL-2 level is still significantly higher compared to healthy subjects.

Different genotypes of the IL-2 gene that we saw in our research may demonstrate genetic predisposition to the disease development. This hypothesis has been proved through analysis of association between polymorphisms and circulating cytokine levels in patients with pulmonary $\mathrm{TB}$, which contributes to pathological changes in serum IL-2 levels in patients with TB on admission to hospital and following two months of chemotherapy.

Furthermore, we observed statistically significant decreased serum levels of anti-inflammatory cytokines IL-4 and IL-10 compared with the third group at the point of treatment onset. It indicates that Th2-lymphocyte activity was decreased prior to treatment. These changes may be associated with pronounced activation of Th1-lymphocytes during augmentation of immunity against tuberculosis in patients with pulmonary TB at the onset of chemotherapy. Changes of IL-4 and IL-10 conducted after two months of therapy, may be associated with the activation of Th2-lymphocytes and, as a result, a certain stabilization of Th1-lymphocytes. Evaluation of serum cytokine levels in patients following two months of anti-TB therapy and equivalent parameters in healthy subjects showed significant IL-4 level reduction in the first group, indicating relative insufficiency of IL-4 level restoration during the second month of treatment.

C589T polymorphism of the $I L-4$ gene and G1082A polymorphism of the $I L-10$ gene are deemed the most important for immunogenetic mechanisms of inflammation in TB patients [25, 26]. We conclude that homozygous genotype (CC) of the $I L-4$ gene and homozygous genotype (GG) of the $I L-10$ gene have a protective effect against infiltrative pulmonary TB.

Moreover, studied cytokine levels and polymorphisms may indicate an impact of polymorphisms on aforementioned interleukins production at the treatment onset and over a course of treatment that has been already shown in previous studies [27]. This finding was supported by significant changes of serum cytokines concentrations in patients with pulmonary TB on admission to hospital and following two months of chemotherapy.

Thus, heterozygous and mutational homozygous genotypes of the $I L-2, I L-4$ and $I L-10$ genes determining production level of studied interleu- kins represent an important risk factor of susceptibility to pulmonary TB development and disease progression into chronic phase. Heterozygous genotype activation of studied interleukin polymorphisms can contribute to MDR TB development through non-stabilized immune response of human body and resistant MTB strains infection prior to chemotherapy and over a course of treatment. Furthermore, it has not been demonstrated what mutations exactly are of crucial importance. We suppose that combination of genotypes but not separate genotypes of the genes plays a key role. The influence of genotypes combinations on susceptibility to infection and sustained bacterial infection is among the perspectives in IL-2, IL-4 and IL-10 immunogenetic studies.

Due to low numbers of study participants our results should be treated as preliminary.

\section{Conclusions}

1. Serum IL-2 level was significantly increased in MDR TB patients compared to the group of patients not colonized by resistant MTB to anti-TB drugs at treatment onset and following two months of treatment. Circulating IL-4 and IL-10 levels were significantly increased in patients not suffering from MDR TB compared to the group of patients with resistant TB at treatment onset and following two months of antimycobacterial chemotherapy.

2. Low IL-4, IL-10 secretion and high serum IL-2 alterations were significantly associated with homozygous (TT) and heterozygous (CT) genotypes of the $I L-4$ gene, homozygous (AA) and heterozygous (GA) genotypes of the $I L-10$ gene as well as homozygous (GG) and heterozygous (TG) genotypes of the $I L-2$ gene in patients with infiltrative pulmonary TB.

3. Genotype CC of C589T polymorphism in the $I L-4$ gene, genotype GG of G1082A polymorphism in the $I L-10$ gene and genotype TT of T330G polymorphism in the $I L-2$ gene are immunogenetic factors exerting a protective effect in patients with pulmonary TB. Heterozygous (TG) genotype of T330G polymorphism in the $I L-2$ gene, CT genotype of C589T polymorphism in the $I L-4$ gene and GA genotype of G1082A polymorphism in the $I L$ 10 gene were significantly the most frequent in the MDR TB patients. Homozygous (TT) genotype of C-589T polymorphism in the IL-4 gene, AA genotype of G-1082A polymorphism in the $I L-10$ gene and GG genotype of 
T-330G polymorphism in the $I L-2$ gene were significantly the most frequent in the group of patients not suffering from resistant TB.

\section{Acknowledgements}

We thank all volunteers who participated in this study. The wholehearted support of clinicians, nurses and lab personnel who contributed their effort made this study possible. Our gratitude is expressed to many experts in TB and immunology fields who kindly shared with us their opinions and critiques prior to and after this study was completed.

\section{Conflict of interest}

The authors declare no conflict of interest.

\section{References:}

1. Isakova ZhT, Goncharova ZK, Iusupova EU et al. Statistically mapping modeling of the spread of rifampicin-resistant $\mathrm{M}$. tuberculosis strains in different regions of the Kyrghyz Republic. Probl Tuberk Bolezn Legk 2007; 7: 33-36.

2. World Health Organization. Global tuberculosis report 2014: WHO report 2014. Geneva, Switzerland, 2014.

3. World Health Organization. Guidelines for surveillance of drug resistance in tuberculosis. Geneva, Switzerland: WHO, 2009.

4. Melnyk VM, Novozhylova IA, Matusevych VG et al. Advantages and limitations of detection of patients with drug-resistant tuberculosis. Ukr Pulmonol J 2013; 2: 15-19.

5. Caminero JA. Multidrug-resistant tuberculosis: epidemiology, risk factors and case finding. The International Journal of Tuberculosis and Lung Disease 2010; 14: 382-390.

6. Melnyk VM, Novozhylova IA, Matusevych VG et al. Analytical view on a problem of drug-resistant tuberculosis: current status, achievements and unsolved issues. Ukr Pulmonol J 2012; $1: 5-7$.

7. Hill AV. The genomics and genetics of human infectious disease susceptibility. Annu Rev Genomics Hum Genet 2001; 2: $373-400$.

8. Moller M, Hoal EG. Current findings, challenges and novel approaches in human genetic susceptibility to tuberculosis Tuberculosis (Edinb) 2010; 90: 71-83.

9. Vannberg F O, Chapman S J, Hill A V. Human genetic susceptibility to intracellular pathogens Immunol Rev 2011; 240: 105-116.

10. Johnson JL, Ssekasanvu E, Okwera A et al. Randomized trial of adjunctive interleukin-2 in adults with pulmonary tuberculosis. Am J Respir Crit Care Med 2003; 168: 185-191.
11. Kissina TE, Freidlin IS, Knoring BE et al. Features of specific immune response in the patients with fibrous/cavernous tuberculosis of lungs. Med Immunol 2006; 8: 501-510.

12. Knight J. Polymorphisms in tumor necrosis factor and other cytokines as risks for infectious diseases and the septic syndrome. Curr Infect Dis 2001; 3: 427-439.

13. Butov DO, Kuzhko MM, Shevchenko OS et al. Changes in cytokines status of patients with recurrent pulmonary tuberculosis receiving chemotherapy. Jacobs Journal of Physiology 2015; 1: 001-006.

14. Abel L, El-Baghdadi J, Bousfiha AA et al. Human genetics of tuberculosis: a long and winding road. Philos Trans R Soc Lond B Biol Sci 2014; 369: 20130428. doi: 10.1098/rstb.2013.0428.

15. Ozhegova DS, Freidin MB, Pusyrev VP. Using the bioinformatic tools to choose the SNPs with highly possible phenotypic effect. Eur J Hum Gen 2008; 16: 397.

16. Peresi E, Ragozo Cardoso Oliveira L, da Silva WL et al. Cytokine polymorphisms, their influence and levels in brazilian patients with pulmonary tuberculosis during antituberculosis treatment. Tuberc Res Treat 2013; 2013: 285094. doi: $10.1155 / 2013 / 285094$

17. Adrian VS. Hill. Evolution, revolution and heresy in the genetics of infectious disease susceptibility. Philos Trans R Soc Lond B Biol Sci 2012; 367: 840-849. doi: 10.1098/ rstb.2011.0275.

18. Mathema B, Lewis JJ, Connors J et al. Molecular epidemiology of mycobacterium tuberculosis among South African gold miners. Ann Am Thorac Soc 2015; 12: 12-20. doi: 10.1513/ AnnalsATS.201404-150OC.

19. Marino JH, Wiele CJ, Everhart IM et al. Attenuation of cytokine responsiveness during $\mathrm{T}$ cell development and differentiation. J Interferon Cytokine Res 2006; 26: 748-759.

20. Ouyang W, Rutz S, Crellin NK et al. Regulation and functions of the IL-10 family of cytokines in inflammation and disease Annu Rev Immunol 2011; 29: 71-109. doi: 10.1146/annurev -immunol-031210-101312.

21. Rook GA, Graham A. Th2 cytokines in susceptibility to tuberculosis. Curr Mol Med 2007; 7: 327-337.

22. Lapach SN, Chubenko AV, Babich PN. Statistical methods in biomedical studies using Excel. Kiev 2000: 320.

23. Berezhnaya NM, Chekhun VF. Immunology of malignant growth. Kiev 2005: 791.

24. Fol M, Druszczynska M, Wlodarczyk M et al. Immune response gene polymorphisms in tuberculosis Acta Biochim Pol 2015; 62: 633-640. doi: 10.18388/abp.2015_1130.

25. Naslednikova IO, Urazova OI, Voronkova OV, et al. Allelic polymorphism of cytokine genes during pulmonary tuberculosis. Bull Exp Biol Med 2009; 148: 175-180.

26. Qi H, Sun L, Jin YQ et al. rs2243268 and rs2243274 of Interleukin-4 (IL-4) gene are associated with reduced risk for extrapulmonary and severe tuberculosis in Chinese Han children. Infect Genet Evol 2014; 23: 121-128. doi: 10.1016/j. meegid.2014.01.031.

27. Laundy G J, Bidwell J L. Human cytokine gene nucleotide sequence alignments: interleukin 4 receptor alpha chain (IL4RA), IL5RA, IL8, IL8RB and IL13. Eur J Immunogenet 2003; 30: $13-87$. 